\title{
Correction to: Intranasal sufentanil given in the emergency department triage zone for severe acute traumatic pain-a randomized double-blind controlled trail: comment
}

\author{
Simon-Pierre Corcostegui ${ }^{1}$. Damien Commeau ${ }^{1}$ - Julien Galant ${ }^{1} \cdot$ Fabien Ramon $^{1}$ - Cédric Boutillier du Retail ${ }^{1}$
}

Published online: 29 March 2019

๑) Società Italiana di Medicina Interna (SIMI) 2019

Correction to: Internal and Emergency Medicine

https://doi.org/10.1007/s11739-019-02069-5

In the original publication, the doses of sufentanil were incorrectly published.

Instead of a dose of $0.6 \mathrm{mg} / \mathrm{kg}$ of sufentanil, the dosage is $0.6 \mu \mathrm{g} / \mathrm{kg}$.

Instead of the dosage of $0.4 \mathrm{mg} / \mathrm{kg}$, the dosage is $0.4 \mu \mathrm{g} /$ $\mathrm{kg}$.

The original article can be found online at https://doi.org/10.1007/ s11739-019-02069-5.

Simon-Pierre Corcostegui

spcorcostegui@gmail.com

Damien Commeau

damien.commeau@gendarmerie.interieur.gouv.fr

Julien Galant

julien.galant@gendarmerie.interieur.gouv.fr

Fabien Ramon

fabien.ramon@gendarmerie.interieur.gouv.fr

Cédric Boutillier du Retail

cedric.boutillier-du-retail@gendarmerie.interieur.gouv.fr

1 French Military Medical Service, 1ère Antenne Médicale Spécialisée, 34 rue de la Martinière, 78000 Versailles,

France 